\title{
CIEP 358: espaço de autonomia e transformação
}

Recebido em 21.12.2013. Aprovado em 28.12. 2013 Avaliado pelo sistema double blind review

\author{
Maristela da Cunha Rodrigues Lyrio \\ maristela.lyrio@globo.com \\ CIEP Brizolão 479 - Mario Simão Assaf - Nova Iguaçu -RJ - Brasil.
}

\section{Resumo}

Conquistar melhores resultados na educação do Estado do Rio de Janeiro é uma decisão que exige esforço e dedicação de todos, pais e alunos, professores, funcionários e gestores. Por isso, as ações propostas e definidas em conjunto pela comunidade escolar serão implementadas visando a permanência dos alunos na escola, a melhoria da aprendizagem e, consequentemente, a melhoria dos resultados nas avaliações externas estaduais e federais.

Os membros da comunidade escolar do CIEP 358 reconhecem o valor da escola pública e sua responsabilidade com a transformação da realidade de nossos alunos e da sociedade em que vivem. Nesta perspectiva surgiu a proposta do Projeto Multidisciplinar CIEP 358: espaço de autonomia e transformação, visando oferecer oportunidades de crescimento e autonomia aos alunos, seguindo o princípio de Aprender a Aprender.

A escola deve ser ambiente de aprendizagem e não deve estar limitada à sala de aula. Com a implementação deste projeto a escola ampliará a utilização das ferramentas das tecnologias da informação e comunicação ultrapassando os muros da escola e aproximando-se de seus alunos e atendendo a diferentes áreas do conhecimento e disciplinas.

Melhorar a qualidade dos serviços oferecidos é a meta de todos e será fruto de um trabalho em conjunto. Assim, toda a equipe escolar estará envolvida no projeto, e este atenderá à totalidade das turmas e turnos, na medida em que haverá a Socialização de ferramentas e oportunidades para todos, gerando autonomia e transformação.

Para a realização deste projeto, o valor solicitado ao edital será de $\mathrm{R} \$ 75.891,20$, destinados à compra de alguns equipamentos para 8 salas de aulas e sala de informática, além da realização de alguns reparos; assim como para despesas correntes, material de consumo e serviços capacitação de profissionais da escola.

O empreendimento, submetido ao Programa de Melhoria da Aprendizagem nas Escolas, da Fundação Novo Brasil - Educação para o Futuro, do qual esperamos o apoio financeiro, é de baixo custo, contudo tem alta perspectiva de sucesso, principalmente pelo esforço e dedicação das equipes discente, docente, pedagógica, administrativa e gestora, como apresentaremos nos próximos capítulos.

Palavras-chaves: Educação. Tecnologias de ensino. Multidisciplinaridade. Plano de empreendimento. 


\section{Contexto da escola}

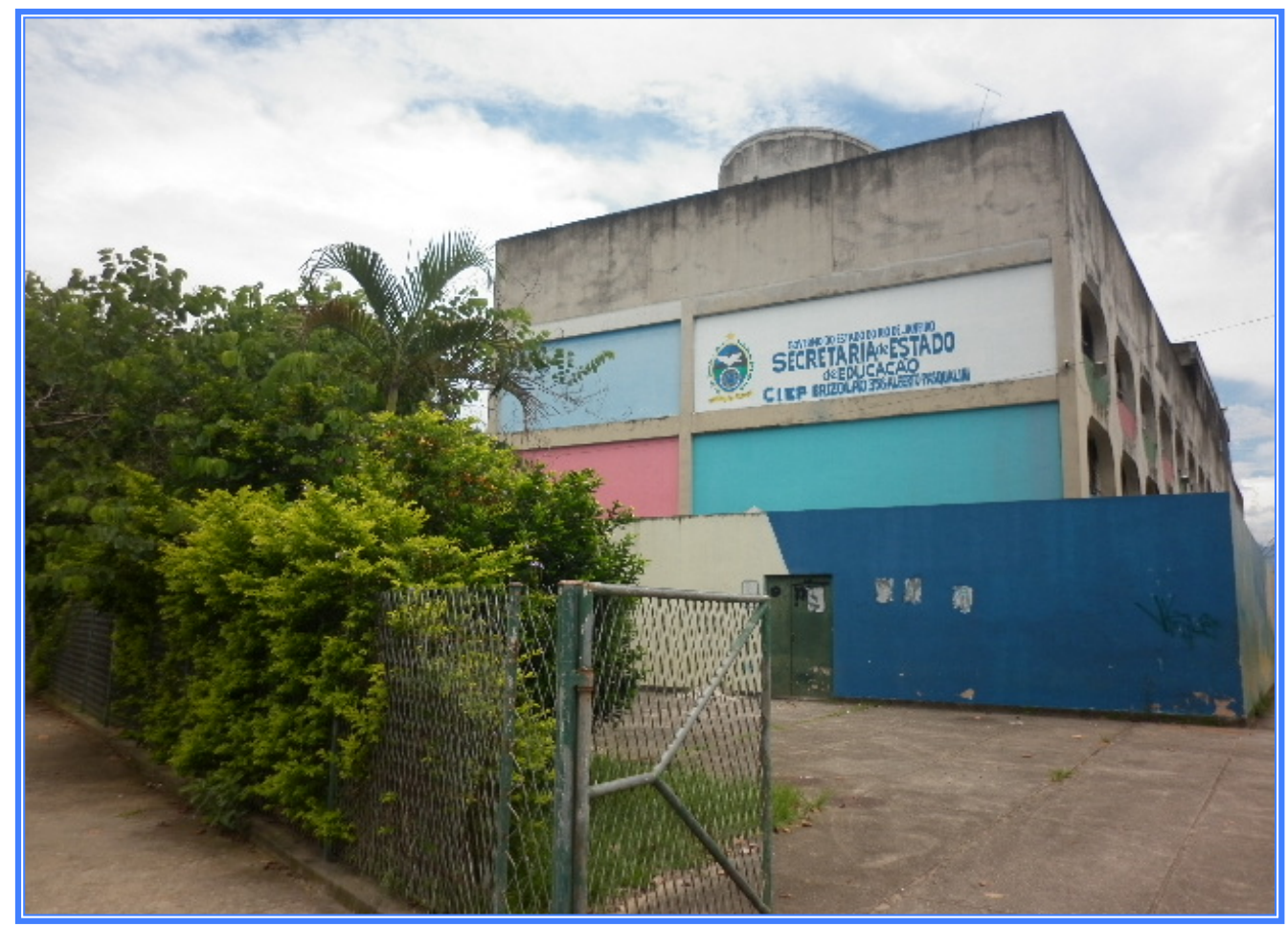

Figura 1: Vista frontal da Unidade Escolar.

Legislação:

1. Decreto de criação: $n^{0}$. 19.598 de 01/02/1994. Parecer 494/93 do Conselho Estadual de Educação, publicado em D.O. do dia 2/02/1994.

2. Denominação: GP - 358 Alberto Pasqualini, Decreto $n^{0}$. 20.439, de 29 de agosto de 1994, publicado em D.O. do dia 30/08/1994.

3. Denominação: CIEP Brizolão - 358 Alberto Pasqualini, Lei $n^{0} .4 .535$, de 04 de abril de 2005, publicado em D.O. do dia 05/04/2005.

Cursos oferecidos:

- Ensino Fundamental - do $7^{\circ}$ ao $9^{\circ}$ ano - Modalidade Regular

- Ensino Médio - Formação Geral - Modalidade Regular

- Ensino Médio e Ensino Fundamental - Programa Autonomia (Aceleração de estudos com vistas à redução da distorção idade/série).

Diretora Geral:

Profa. Maristela da Cunha Rodrigues Lyrio.

Diretores Adjuntos:

Profa. Darcy Ivone Simão e Prof. Luiz Gonzaga Lizardo.

\section{Marco Referencial}

Missão: Oferecer ensino de qualidade aos alunos, socializar os recursos tecnológicos, didáticos e de informação disponíveis a toda a comunidade, com vistas à transformação social da comunidade.

Visão: Ser uma escola de referência em nosso estado, reconhecida pelas práticas educativas exitosas, pelo trabalho participativo e integrado da equipe, pelos resultados excelentes obtidos nas avaliações e pelo respeito e bom relacionamento com a comunidade até dezembro de 2014. 


\section{CIEP 358:espaço de autonomia e transformação}

O CIEP Brizolão 358 - Alberto Pasqualini, fundado na $3^{\circ}$ fase do Programa Especial de Educação, em 1994, é um CIEP compacto (biblioteca e quadra de esportes estão localizadas na cobertura do prédio). Funciona em três turnos, atendendo a 1085 alunos. Contem 16 salas de aulas, sala de vídeo (45 pessoas), auditório (100 pessoas), laboratório de Informática (10 computadores). A biblioteca, que também atende à comunidade externa, tem acervo diversificado com mais de 5000 obras literárias e científicas e o Laboratório de Ciências está aquém das necessidades de alunos e professores. Após quase 20 anos da sua construção, a escola necessita reformas e obras de recuperação da estrutura.

Apesar das diversidades, a escola é reconhecida na comunidade através de sua ações, tais como, orientações à coleta seletiva de lixo, coleta de óleo de cozinha, de pilhas e baterias, e de plantio de mudas. Em 2010, 2011 e 2012 recebeu prêmios pelo $2^{\circ}$ lugar na Campanha Estudar Vale à Pena; $2^{\circ}$ lugar no Evento Superação em 2011 e 2012; em 2010, 5 de seus alunos ficaram entre os 10 primeiros em melhor desempenho na Avaliação Externa do Projeto Entre Jovens, todos os projetos com apoio do Instituto Unibanco; em 2012, a escola foi bonificada pela SEEDUC por seu desempenho. Esperamos continuar desenvolvendo ações que ofereçam oportunidades de crescimento para nossos alunos.

Nesta perspectiva, a escola, em 2012, firmou parceria com o Instituto Empreender, que desde então, oferece Curso de Empregabilidade e Tecnologia aos nossos jovens do Ensino Médio. E, este ano, firmou parceria com o SESI / FIRJAN (complexo localizado em frente à escola) para a oferta de cursos livres de línguas, informática e matemática.

\section{Alunos}

Perfil: 1085 alunos do próprio bairro, contudo há grande número de alunos advindos de outros bairros, inclusive bairros distantes e outros municípios.

Demonstrativo de turmas e alunos:

\begin{tabular}{|l|l|c|c|c|}
\hline \multicolumn{1}{|c|}{ Curso } & Modalidade & Série & $\mathbf{N}^{0}$ de alunos & $\mathbf{N}^{\mathbf{0}}$ de turmas \\
\hline Fundamental & Regular & $7^{\mathrm{a}}$ & 124 & 4 \\
\hline Fundamental & Regular & $8^{\mathrm{a}}$ & 160 & 5 \\
\hline Fundamental & Regular & $9^{\mathrm{a}}$ & 158 & 5 \\
\hline Médio & Regular & $1^{0}$ & 235 & 9 \\
\hline Médio & Regular & $2^{0}$ & 219 & 6 \\
\hline Médio & Regular & $3^{0}$ & 148 & 4 \\
\hline Fundamental & Autonomia & Aceleração & 22 & 1 \\
\hline Médio & Autonomia & Aceleração & 19 & 1 \\
\hline
\end{tabular}

Fonte: Sistema Conexão

\section{Professores}

A equipe gestora é composta de uma Diretora Geral e um Diretor Adjunto, aprovados em Processo Seletivo Interno e uma Diretora Adjunta cujo Plano de Gestão fora aprovado pela comunidade no último processo de eleitoral. A equipe pedagógica é composta por uma Coordenadora Pedagógica e duas Orientadoras Educacionais. Todos os 41 professores regentes de turma da unidade são graduados em suas disciplinas, assim dispostos: 


\begin{tabular}{|c|c|c|c|}
\hline Disciplinas & Graduados & Pós-graduados & Mestres \\
\hline Artes & 2 & & \\
\hline Ciências e Biologia & 1 & 2 & \\
\hline Educação Física & 1 & 1 & \\
\hline Espanhol & & 1 & \\
\hline Filosofia & 1 & & \\
\hline Física & 2 & & \\
\hline Geografia & 1 & 3 & \\
\hline História & & 2 & 1 \\
\hline Inglês & 1 & 2 & \\
\hline Língua Portuguesa & 2 & 4 & \\
\hline Matemática & 4 & 3 & \\
\hline Química & & 3 & \\
\hline Sociologia & & 1 & 1 \\
\hline Ensino Religioso & & 2 & \\
\hline Totais & 15 & 24 & 2 \\
\hline
\end{tabular}

Fonte: Arquivo do Departamento Gestão de Pessoas da Unidade Escolar.

A equipe de professores é formada, grande parte, por Docentes 40 horas (30 tempos em sala de aula), e ainda professores com duas matrículas lotados na mesma escola, o que reduz o número de professores necessários para atender à escola.

\section{Características mais marcantes do local onde a escola se insere}

O Bairro da Luz, onde a escola está localizada, é nitidamente um bairro residencial da área urbana do Município de Nova Iguaçu, apresenta um significativo número de condomínios fechados. A maior parte de suas ruas são pavimentadas e possuem saneamento básico. Localizada em frente ao Complexo SENAI SESI, a escola conta com parcerias com ofertas de cursos livres gratuitos para seus alunos e funcionários. Há um pequeno comércio nas proximidades da escola, contudo, afora alguns "campinhos de futebol", o bairro não oferece qualquer outro tipo de lazer para a sua juventude. A comunidade reconhece 0 trabalho desenvolvido na escola, entretanto, ainda há o preconceito de que os "CIEPs foram feitos para serem escolas marginais", ocorrendo alguns episódios de pichações.

Em um bairro bastante próximo à escola está localizada uma grande indústria de cosméticos, o que representa uma oportunidade de novas parcerias. Reconhecidamente não há cursos técnicos da rede pública nas proximidades e, menos ainda, mão de obra especializada para atender à demanda. 


\section{CIEP 358:espaço de autonomia e transformação}

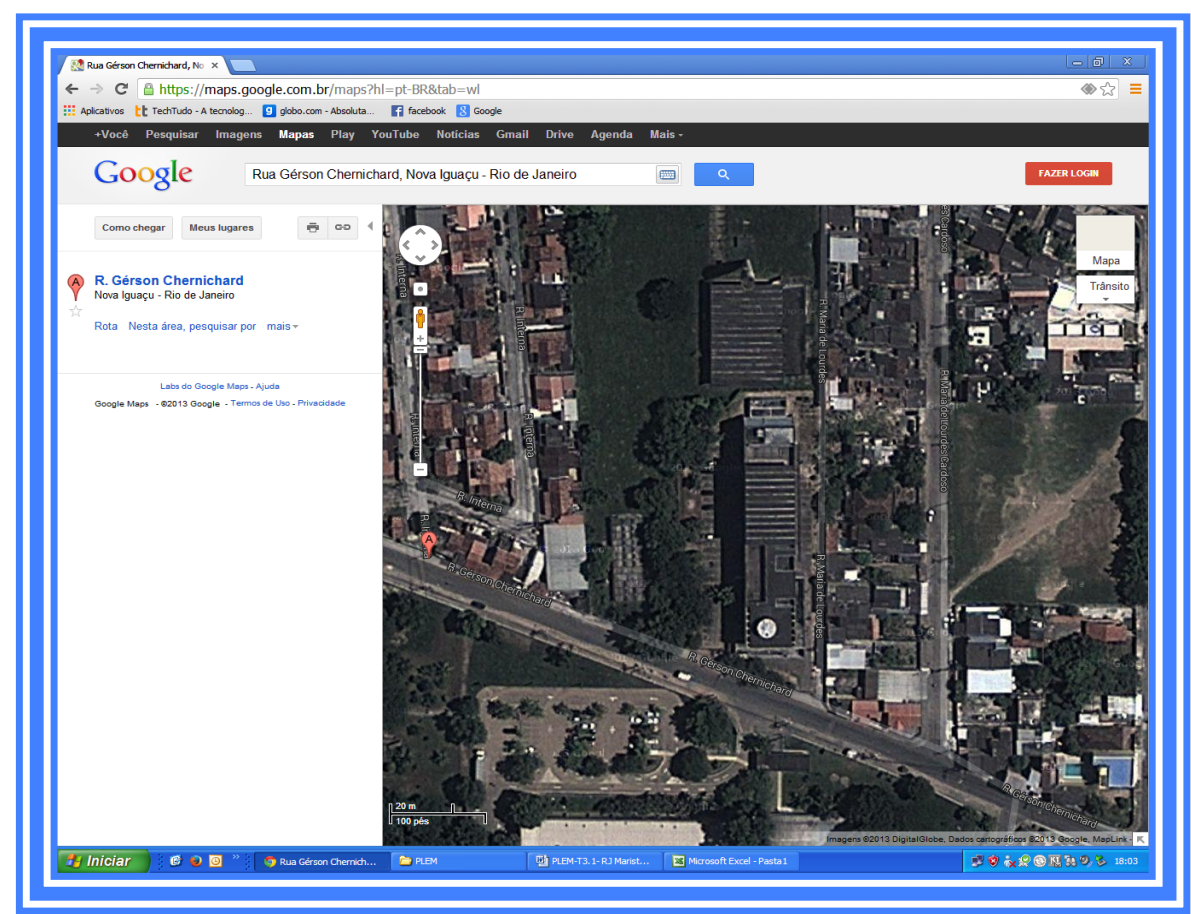

\section{Identificação do problema ou da oportunidade}

Com uma educação de qualidade a escola pública pode fazer brasileiros melhores. Esta declaração incentivanos a reconhecer a importância dos papeis da escola pública e dos educadores. Baseados nas avaliações internas dos resultados do desempenho dos alunos, nos números de evadidos e retidos na série, além da reunião de avaliação anual, concluímos que estamos caminhando, contudo, ainda há muito a fazer.

\section{Demonstrativo de 2012 e metas para 2013}

Avaliação Histórica do IDEB e Metas Projetadas - $9^{\circ}$ ano do Ensino Fundamental

\begin{tabular}{|c|c|c|c|c|c|c|c|c|c|c|c|c|}
\hline & \multicolumn{4}{|c|}{ Ideb Observado } & \multicolumn{8}{|c|}{ Metas Projetadas } \\
\hline Escola * & 2005 & 2007 & 2009 & 2011 & 2007 & 2009 & 2011 & 2013 & 2015 & 2017 & 2019 & 2021 \\
\hline $\begin{array}{l}\text { CIEP } \\
\text { PASIZOLALAO } 358 \text { ALBERTO } \\
\text { PASINI }\end{array}$ & 2.7 & 3.0 & 3.2 & 2.9 & 2.8 & 2.9 & 3.2 & 3.6 & 4.0 & 4.3 & 4.6 & 4.8 \\
\hline
\end{tabular}

Fonte: MEC - INEP

Um dos principais problemas abordados para justificar a retenção e o baixo desempenho no IDEB foi 0 fato de que os alunos não conseguem interpretar e construir textos coerentes. Assim, apresentam grandes dificuldades não somente em Língua Portuguesa, mas também nas demais disciplinas. Não entendem o que lêem e não expressam suas idéias corretamente. A cada nova turma verificamos que os alunos lêem menos. Buscar soluções para contribuir para diferentes letramentos e desenvolvimento da expressão oral e escrita são ações fundamentais, já implementadas na escola, mas que precisam ser fortalecidas para a melhoria do desempenho dos alunos.

A atratividade do ambiente externo e do acesso à informações que independem da sala de aula têm levado muitos alunos a desvalorizarem a escola. Não utilizar recursos tecnológicos atuais como ferramentas que favorecem a aprendizagem é negar o direito de nossos alunos de estarem atualizados e conectados com 0 mundo. 
Observamos que as tecnologias utilizadas na escola podem melhorar as técnicas de ensino, a atratividade das aulas e, consequentemente promover um melhor aprendizado dos nossos alunos, que muito frequentemente estão mais atentos às mudanças e ávidos por novos desafios.

Em 2008, a escola recebeu do MEC 10 computadores PROINFO para criar o Laboratório de Informática da escola. Foi um grande avanço, desde que nada havia antes disponível para o aluno. Assim, o laboratório atende a apenas 10 alunos a cada atividade. O tempo também é um obstáculo, visto que os computadores já estão ultrapassados e muito lentos. Nosso laboratório comporta 20 máquinas, que podem ser utilizadas por 20 alunos, otimizando o espaço.

No início do ano nossa escola recebeu uma lousa eletrônica - composta de um receptor e uma caneta, que, acoplados ao projetor PROINFO (computador interativo utilizado em escolas públicas). Professores relataram que, nas aulas em que utilizaram a lousa eletrônica, a concentração de seus alunos aumentou e que se mostraram mais participativos durante as aulas. Turmas de Ensino Médio produziram, inclusive, materiais para serem apresentados em seminários e projetos.

Observando os resultados obtidos com o uso do laboratório e da lousa eletrônica, nossa equipe identificou duas oportunidades para a elaboração de um projeto multidisciplinar visando a melhoria da aprendizagem na escola. O Projeto Multidisciplinar CIEP 358: Espaço de Autonomia e Transformação destina-se a promover a aprendizagem segundo o princípio Aprender a Aprender, com vistas à autonomia e transformação da realidade social de nossos alunos.

Novos computadores no laboratório permitirão maior acesso aos alunos e lousas eletrônicas em oito, das dezesseis, salas de aula impactarão na melhoria das práticas pedagógicas, atingindo a todos os cursos, modalidades e turnos da unidade escolar, visto que poderá haver um rodízio de utilização das salas equipadas. Assim, $100 \%$ dos alunos podem ser atendidos.

Equipes pedagógica e docente motivadas, equipe discente com potencial e espaço físico disponível são fatores impactantes para a realização e sucesso deste projeto porque a revitalização do Laboratório de Informática e a instalação de lousas eletrônicas poderão ser utilizados por qualquer professor em qualquer disciplina, conteúdo e atividades. Socialização de ferramentas e oportunidades para todos, gerando autonomia e transformação.

\section{Caracterização do projeto Foco do projeto}

O Projeto Multidisciplinar CIEP 358: espaço de autonomia e transformação atenderá aos alunos da unidade escolar do $7^{\circ}$ ano do Ensino Fundamental ao $3^{\circ}$ ano do Ensino Médio através de salas de aulas equipadas com lousa eletrônica e um laboratório equipado com novos computadores com acesso às informações na internet.

Este projeto tem como objetivo a aprendizagem que vem e vai para além dos muros da escola. Além do professor, as informações vêm de fora e acabam por saírem da escola na medida em que a socialização dos recursos tecnológicos e as possibilidades de transformação social geram impacto no ambiente social. As ações deste projeto baseiam-se nos Princípios e Fins da Educação Nacional, Lei $n^{0}$ 9.394, de 20 de dezembro de 1996.

Art. $2^{\circ}$. A educação, dever da família e do Estado, inspirada nos princípios de liberdade e nos ideais de solidariedade humana, tem por finalidade 0 pleno desenvolvimento do educando, seu preparo para o exercício da cidadania e sua qualificação para o trabalho. 


\section{CIEP 358:espaço de autonomia e transformação}

\section{Atividades a serem realizadas}

Dentre as inúmeras possibilidades de atividades a serem realizadas com a implementação deste projeto apresentamos:

\section{Agendamento das salas de aulas e laboratório de informática}

Professores deverão agendar a utilização das salas equipadas com as lousas eletrônicas e laboratório de informática devido à necessidade de rodízio. Como este já é um procedimento habitual na escola para a utilização da Sala de Vídeo, Laboratório de Informática e Auditório, então, não será fator de fraqueza para a realização das atividades.

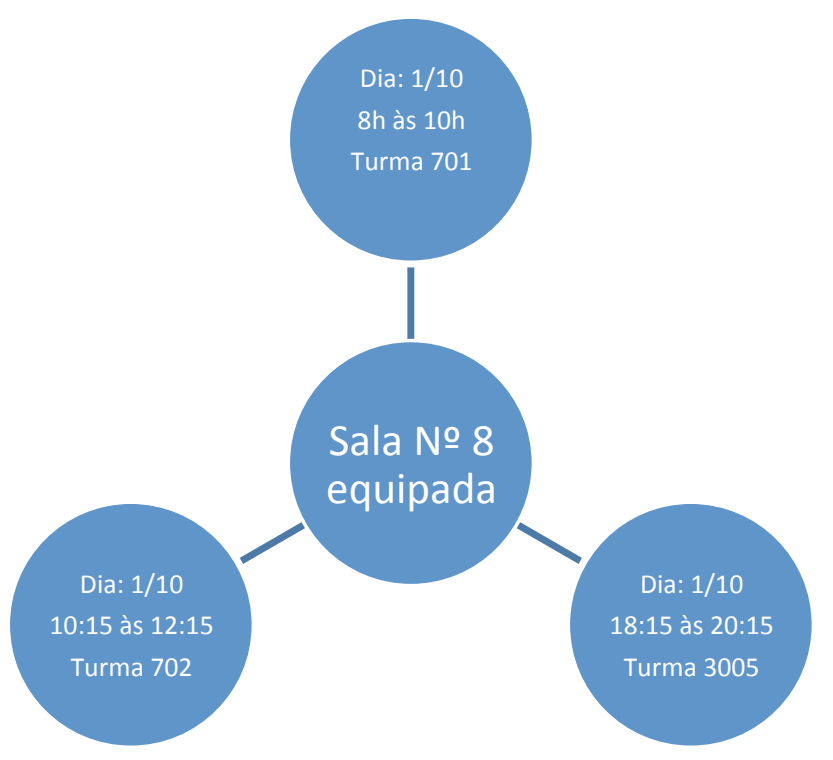

\section{Ensino das diferentes disciplinas}

- Navegação por sites educativos;

- Criação de tabelas e gráficos;

- Criação de textos;

- Recursos de criação de desenhos e slides;

- Utilização de mapas em tempo real;

- Ferramentas para o ensino das diferentes disciplinas;

- Acesso à informações diversas;

- Gravar aulas e criar banco de aulas para possíveis faltas de professores e/ou aulas de revisão;

- Registros de boas práticas pedagógicas;

- Apresentação de vídeos;

- Criação de vídeos e outras mídias;

- Interatividade com alunos e professores;

- Criação de jornais digitais;

- Desenvolvimento de plano de comunicação entre a comunidade escolar;

- Apresentação de resultados de desempenho das turmas;

- Comparação de diferentes fontes em curto espaço de tempo;

- Clipes de músicas em diversos idiomas para o ensino de línguas;

- Apresentação de filmes ou trechos de filmes.

- E ... onde sua imaginação puder chegar. 


\section{Viabilidade e continuidade do projeto}

Além do acesso à internet no Laboratório de Informática, a escola possui rede wifi disponível a professores para que possam realizar diferentes atividades com suas turmas. Há diversos materiais digitais prontos e disponibilizados pela SEEDUC através dos sites Conexão Professor e Conexão Aluno. Somados às infinitas possibilidades de informações encontradas na internet, desde documentários a atualidades.

Os resultados poderão ser avaliados a partir dos registros de utilização das salas, das disciplinas e turmas. A equipe poderá comparar os resultados de desempenho e freqüência das turmas, observando se as turmas cujos professores agendam mais as salas apresentam índices melhores do que aquelas cujos professores não utilizam ou utilizam menos as salas equipadas.

Atualmente percebemos que quando as turmas estão na sala de vídeo, onde temos a lousa eletrônica instalada, ou no auditório, apresentam maior interesse nas atividades, além da redução de eventos de indisciplina. Assim, vislumbramos grandes possibilidades de melhoria na aprendizagem com este projeto.

\section{Estratégia de implementação Análise Estratégica}

\begin{tabular}{|c|c|}
\hline \multicolumn{2}{|c|}{ Matriz SWOT/FOFA } \\
\hline FORÇAS & FRAQUEZAS \\
\hline $\begin{array}{l}\text { Equipes gestora, pedagógica e docente comprometidas com a } \\
\text { melhoria da qualidade do ensino. }\end{array}$ & Resistência de alguns professores às novas tecnologias \\
\hline Espaço físico disponível. & \multirow{2}{*}{ Alto índice de distorção idade-série } \\
\hline Alunado motivado pelo uso de novas tecnologias. & \\
\hline $\begin{array}{l}\text { Equipe de Agentes Jovens (representantes de turmas) } \\
\text { comprometida. }\end{array}$ & \multirow{2}{*}{$\begin{array}{l}\text { Desvalorização das aulas dos professores que não utilizarem } \\
\text { os novos recursos pelos alunos. }\end{array}$} \\
\hline Sucesso das ações com os poucos recursos que dispomos. & \\
\hline OPORTUNIDADES & AMEAÇAS \\
\hline $\begin{array}{l}\text { Parcerias: SESC e Instituto Empreender que oferecem cursos } \\
\text { aos nossos alunos utilizando novas tecnologias. }\end{array}$ & Descontinuidade das parcerias. \\
\hline Acesso à Internet no laboratório e wi-fi em toda escola. & Evasão por motivo de trabalho. \\
\hline Maior parte do alunado ambientado às novas tecnologias. & Pouca participação dos pais nas ações da escola. \\
\hline $\begin{array}{l}\text { Manutenção e substituição de equipamentos obsoletos (recursos } \\
\text { do PLEM). }\end{array}$ & $\begin{array}{l}\text { Manutenção e substituição de equipamentos por desgaste } \\
\text { pelo uso (recursos da SEEDUC ). }\end{array}$ \\
\hline
\end{tabular}

\section{Objetivos, metas e estratégias}

\begin{tabular}{|l|l|l|}
\hline Objetivos & Metas & Estratégias \\
\hline $\begin{array}{l}\text { Melhorar a infraestrutura da } \\
\text { escola através da aquisição e } \\
\text { instalação de novos recursos } \\
\text { tecnológicos. }\end{array}$ & $\begin{array}{l}\text { Ampliar a oferta de salas de } \\
\text { aulas equipadas com lousa } \\
\text { eletrônica de 1 para 9 salas } \\
\text { até dezembro de 2013. }\end{array}$ & $\begin{array}{l}\text { - Capacitar professores, estagiários e monitores nos nova ferramenta para a melhoria da atratividade } \\
\text { das aulas. }\end{array}$ \\
\hline
\end{tabular}




\section{CIEP 358:espaço de autonomia e transformação}

\begin{tabular}{|c|c|c|}
\hline $\begin{array}{l}\text { Melhorar o laboratório de } \\
\text { informática. }\end{array}$ & $\begin{array}{l}\text { Ampliar o } n^{0} \text { de máquinas } \\
\text { atualizadas disponíveis no } \\
\text { laboratório de informática de } \\
10 \text { para } 20 \text { até dezembro de } \\
2013 \text {. }\end{array}$ & $\begin{array}{l}\text { - Disponibilizar os recursos tecnológicos a um maior } n^{0} \text { de } \\
\text { usuários ao mesmo tempo, facilitando a aplicação de } \\
\text { atividades com, pelo menos } 50 \% \text { da turma. }\end{array}$ \\
\hline $\begin{array}{l}\text { Contribuir para a melhoria da } \\
\text { aprendizagem dos alunos. }\end{array}$ & $\begin{array}{l}\text { Aumentar o índice de } \\
\text { aprovação de } 80 \% \text { para } 82 \% \\
\text { até dezembro de } 2013 .\end{array}$ & $\begin{array}{l}\text { - Identificar os alunos com médias inferiores a } 5 \text { e as } \\
\text { disciplinas críticas; } \\
\text { - Utilizar aulas gravadas para a recuperação de conteúdos, } \\
\text { através dos novos recursos tecnológicos adquiridos. }\end{array}$ \\
\hline $\begin{array}{l}\text { Aumentar o índice } \\
\text { permanência na escola. }\end{array}$ & $\begin{array}{l}\text { Aumentar de } 93 \% \text { para } 95 \% \\
\text { até dezembro de } 2013 \text {. }\end{array}$ & $\begin{array}{l}\text { - Identificar os problemas enfrentados pelos alunos; } \\
\text { - Realizar ações de recuperação de alunos evadidos; } \\
\text { - Utilizar aulas gravadas para a recuperação de conteúdos, } \\
\text { através dos novos recursos tecnológicos adquiridos. }\end{array}$ \\
\hline
\end{tabular}

\section{Plano de Ação}

\begin{tabular}{|c|c|c|c|c|c|c|}
\hline Ação & Justificativa & Responsável & Espaço & Período & Procedimentos & Custo \\
\hline $\begin{array}{lr}\text { Adquirir material } \\
\text { necessário para } \\
\text { pequenos reparos e } \\
\text { contratar serviço. }\end{array}$ & $\begin{array}{l}\text { Preparar as salas e } \\
\text { laboratório } \quad \text { de } \\
\text { informática. }\end{array}$ & $\begin{array}{l}\text { Diretor } \\
\text { Adjunto }\end{array}$ & $\begin{array}{ll}\text { Sala } & \text { da } \\
\text { direção } & \end{array}$ & Semana 1 & $\begin{array}{lr}\text { Utilizando } & \text { a } \\
\text { internet } & \text { e/ou } \\
\text { telefone. } & \end{array}$ & 330,00 \\
\hline $\begin{array}{lr}\text { Adquirir } & 10 \\
\text { computadores e } 8 \\
\text { lousas eletrônicas. }\end{array}$ & $\begin{array}{lr}\text { Equipar as } & \text { salas e } \\
\text { laboratório } & \text { de } \\
\text { informática. } & \\
\end{array}$ & Diretora Geral & $\begin{array}{ll}\text { Sala } & \text { da } \\
\text { direção } & \end{array}$ & Semana 1 & $\begin{array}{ll}\text { Utilizando } & \text { a } \\
\text { internet. }\end{array}$ & 32711,20 \\
\hline $\begin{array}{l}\text { Acompanhar } \\
\text { realização dos } \\
\text { reparos. }\end{array}$ & $\begin{array}{lcr}\text { Verificar } & \text { se } & \text { os } \\
\text { serviços } & \text { estão } & \text { de } \\
\text { acordo } & \text { com } & \text { o } \\
\text { solicitado. } & & \end{array}$ & $\begin{array}{l}\text { Diretor } \\
\text { Adjunto }\end{array}$ & $\begin{array}{l}\text { Salas } \\
\text { selecionada } \\
\text { s }\end{array}$ & $\begin{array}{l}\text { Semanas } 2 \\
\text { e3. }\end{array}$ & $\begin{array}{ll}\text { Visitando } & \text { os } \\
\text { espaços } & \\
\text { selecionados. } & \end{array}$ & $\begin{array}{l}\text { Contrapartid } \\
\text { a da escola. }\end{array}$ \\
\hline $\begin{array}{l}\text { Realizar } \\
\text { capacitação. }\end{array}$ & $\begin{array}{lr}\text { Capacitar } & \\
\text { educadores, } & \\
\text { estagiários } & \text { e } \\
\text { monitores } & \text { nos } \\
\text { equipamentos. } & \end{array}$ & Diretora Geral & $\begin{array}{l}\text { Salas } \\
\text { selecionada } \\
\text { s }\end{array}$ & $\begin{array}{l}\text { Semana } \\
5\end{array}$ & $\begin{array}{lr}\text { Contratando } & \\
\text { empresa } & \text { e } \\
\text { Treinando } & \text { os } \\
\text { profissionais } & \text { da } \\
\text { escola. } & \end{array}$ & 4500,00 \\
\hline $\begin{array}{l}\text { Realizar campanha } \\
\text { de comunicação }\end{array}$ & $\begin{array}{l}\text { Divulgar os novos } \\
\text { recursos à toda } \\
\text { comunidade escolar. }\end{array}$ & $\begin{array}{l}\text { Animador } \\
\text { Cultural }\end{array}$ & $\begin{array}{l}\text { Via e-mails, } \\
\text { facebook, } \\
\text { reuniões de } \\
\text { pais, de } \\
\text { alunos, } \\
\text { fanzine, } \\
\text { murais e } \\
\text { central de } \\
\text { som. }\end{array}$ & $\begin{array}{l}\text { Semanas } 4 \\
\text { e } 5\end{array}$ & $\begin{array}{l}\text { Apresentando á } \\
\text { comunidade } \\
\text { escolar os novos } \\
\text { recursos } \\
\text { tecnológicos, } \\
\text { suas } \\
\text { possibilidades de } \\
\text { utilização e } \\
\text { contribuição para } \\
\text { a aprendizagem. }\end{array}$ & $\begin{array}{l}\text { Contrapartid } \\
\text { a da escola. }\end{array}$ \\
\hline $\begin{array}{l}\text { Adquirir material de } \\
\text { consumo: resmas de } \\
\text { papel, banners, } \\
\text { toner para } \\
\text { duplicadora, } \\
\text { lanches, ingressos } \\
\text { de teatro, bottons e } \\
\text { brindes. }\end{array}$ & $\begin{array}{l}\text { Fornecer de material } \\
\text { para } \\
\text { desenvolvimento do } \\
\text { projeto }\end{array}$ & $\begin{array}{l}\text { Diretor } \\
\text { Adjunto }\end{array}$ & $\begin{array}{l}\text { Salas } \\
\text { selecionada } \\
\text { s }\end{array}$ & $\begin{array}{l}\text { Semana } \\
1\end{array}$ & $\begin{array}{lr}\text { Utilizando } & \text { a } \\
\text { internet } & \text { para } \\
\text { cotações } & \text { e } \\
\text { compra. } & \end{array}$ & 29500,00 \\
\hline $\begin{array}{l}\text { Oportunizar acesso } \\
\text { a } \quad \text { atividades } \\
\text { culturais. }\end{array}$ & $\begin{array}{l}\text { Premiar as turmas } \\
\text { que atingirem as } \\
\text { metas. }\end{array}$ & Diretora Geral & $\begin{array}{l}\text { Salas } \\
\text { selecionada } \\
\text { s }\end{array}$ & $\begin{array}{l}\text { Semana } \\
1\end{array}$ & $\begin{array}{lr}\text { Utilizando } & \text { a } \\
\text { internet } & \text { para } \\
\text { cotações } & \text { e } \\
\text { contratação. } & \end{array}$ & 8850,00 \\
\hline
\end{tabular}




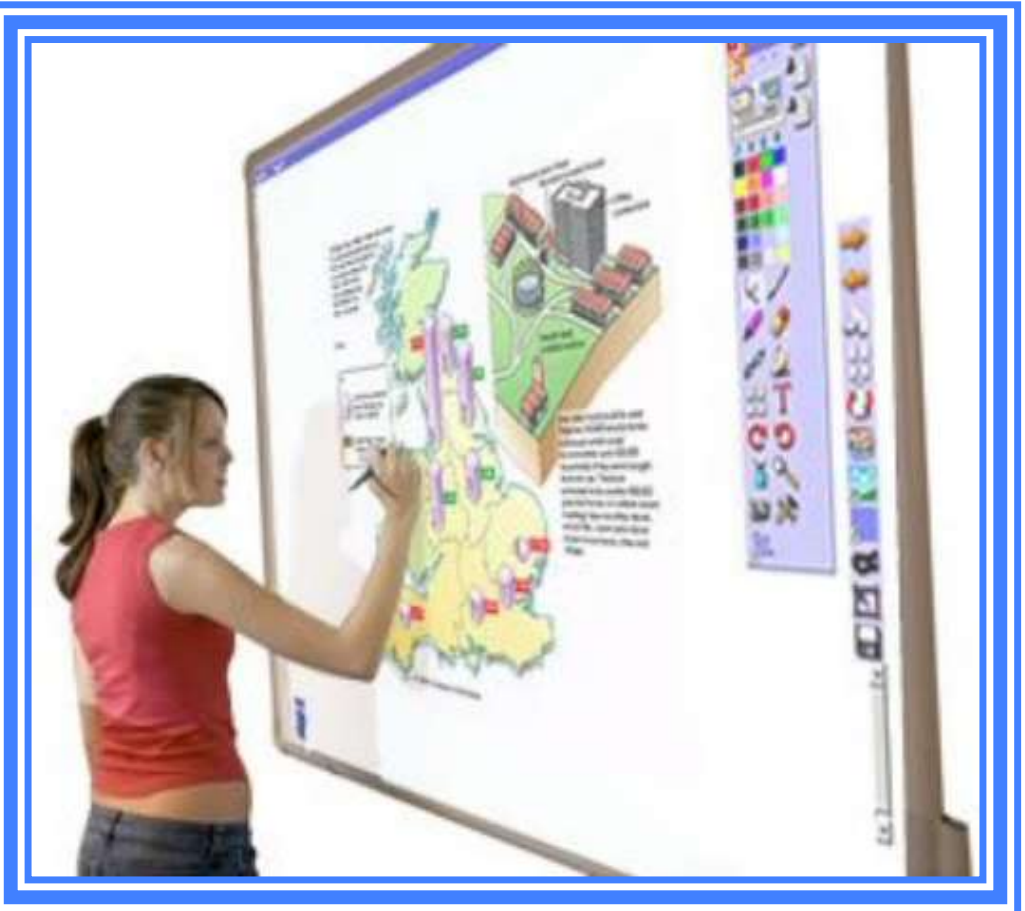

Fonte: i645.photobucket.com

\section{Recursos necessários}

\begin{tabular}{|c|c|c|}
\hline O que vou precisar & Descrição & Origem dos recursos \\
\hline $\begin{array}{l}\text { Pequenos reparos nos } \\
\text { espaços disponibilizados. }\end{array}$ & $\begin{array}{l}\text { Instalação de } 10 \text { tomadas no } \\
\text { laboratório de informática; } \\
\text { Pintura de } 8 \text { salas de aulas e do } \\
\text { laboratório de informática. }\end{array}$ & $\begin{array}{l}\text { Através do Edital nº } 2 \text { - Projeto Inovadores } \\
\text { em Educação, da Fundação Novo Brasil. }\end{array}$ \\
\hline Compra de equipamentos. & $\begin{array}{l}10 \text { computadores; } \\
8 \text { lousas eletrônicas. }\end{array}$ & $\begin{array}{l}\text { Através do Edital nº } 2 \text { - Projeto Inovadores } \\
\text { em Educação, da Fundação Novo Brasil. }\end{array}$ \\
\hline $\begin{array}{l}\text { Cuidar dos ambientes e } \\
\text { equipamentos. }\end{array}$ & $\begin{array}{l}\text { Realizar manutenção periódica nos } \\
\text { ambientes e equipamentos. }\end{array}$ & Contrapartida da escola. \\
\hline $\begin{array}{l}\text { Contratação de empresa } \\
\text { para capacitação. }\end{array}$ & $\begin{array}{l}\text { Realizar treinamento dos profissionais } \\
\text { da escola. }\end{array}$ & $\begin{array}{l}\text { Através do Edital n } 2 \text { - Projeto Inovadores } \\
\text { em Educação, da Fundação Novo Brasil. }\end{array}$ \\
\hline $\begin{array}{l}\text { Contratação de empresa } \\
\text { para transporte de alunos e } \\
\text { professores acompanhantes. }\end{array}$ & $\begin{array}{l}\text { Realizar visitas culturais com os } \\
\text { alunos. }\end{array}$ & $\begin{array}{l}\text { Através do Edital n } 2 \text { - Projeto Inovadores } \\
\text { em Educação, da Fundação Novo Brasil. }\end{array}$ \\
\hline $\begin{array}{l}\text { Compra de material de } \\
\text { consumo. }\end{array}$ & Manutenção das ações. & $\begin{array}{l}\text { Através do Edital n } 2 \text { - Projeto Inovadores } \\
\text { em Educação, da Fundação Novo Brasil. }\end{array}$ \\
\hline
\end{tabular}




\section{CIEP 358:espaço de autonomia e transformação}

\section{Acompanhamento dos resultados}

\begin{tabular}{|c|c|c|c|}
\hline Ação & Período & Indicadores & Responsável \\
\hline $\begin{array}{l}\text { Identificação de alunos faltosos } \\
\text { para ações de retorno. }\end{array}$ & $\begin{array}{l}\text { A cada } \\
10 \text { dias. }\end{array}$ & $\begin{array}{l}N^{0} \text {. de alunos faltosos antes da utilização dos } \\
\text { recursos } / n^{0} \text {. de alunos faltosos após a utilização } \\
\text { dos recursos }\end{array}$ & $\begin{array}{l}\text { Orientadora } \\
\text { Educacional }\end{array}$ \\
\hline $\begin{array}{l}\text { Identificação de alunos com } \\
\text { médias inferiores a } 5 \text { para } \\
\text { ações de recuperação de } \\
\text { conteúdo. }\end{array}$ & Bimestral & $\begin{array}{l}\mathrm{N}^{0} \text {. de alunos com médias inferiores antes da } \\
\text { utilização dos recursos } / \mathrm{n}^{0} \text {. de alunos médias } \\
\text { inferiores após a utilização dos recursos }\end{array}$ & $\begin{array}{l}\text { Coordenadora } \\
\text { Pedagógica }\end{array}$ \\
\hline $\begin{array}{l}\text { Acompanhamento dos } \\
\text { agendamentos das salas e } \\
\text { recursos. }\end{array}$ & Semanal & $\begin{array}{l}\mathrm{N}^{0} \text {. de agendamentos das salas e laboratório de } \\
\text { informática, no Caderno de agendamentos }\end{array}$ & Diretor Adjunto \\
\hline $\begin{array}{l}\text { Identificação das disciplinas } \\
\text { críticas (mais de } 20 \% \text { das } \\
\text { médias inferiores a } 5 \text { ). }\end{array}$ & Bimestral & $\begin{array}{l}\mathrm{N}^{0} \text {. de disciplinas críticas antes do projeto / } \mathrm{N}^{0} \text {. de } \\
\text { disciplinas críticas após o início do projeto }\end{array}$ & Direção Geral \\
\hline Ouvir a equipe & Bimestral & $\begin{array}{l}N^{0} \text {. de professores satisfeitos com os novos } \\
\text { recursos } X n^{0} \text {. de professores insatisfeitos } / n^{0} \text {. de } \\
\text { professores }\end{array}$ & Direção Geral \\
\hline Ouvir os alunos & Bimestral & $\begin{array}{l}N^{0} \text {. de alunos satisfeitos com os novos recursos } X \\
n^{0} \text {. de alunos insatisfeitos / total de alunos }\end{array}$ & Agentes Jovens \\
\hline
\end{tabular}

\section{Marketing e comunicação \\ Composto de comunicação}

A comunidade escolar, como não poderia deixar de ser, é heterogênea, composta por pessoas de diferentes segmentos, idades e, consequentemente, interesses. Assim, o planejamento da Comunicação e Marketing do Projeto CIEP 358: espaço de autonomia e transformação combinará diferentes ferramentas do composto de comunicação com o objetivo de atingir a comunidade interna e externa focando seus diferentes clientes e usuários.

Composto de comunicação:

endomarketing através de e-mails aos professores e demais funcionários da escola, divulgação em reuniões de professores, reuniões de representantes de turmas, murais e som ambiente;

fanzine criado pelos Agentes Jovens e dirigido aos alunos;

postagens no facebook ;

- afixação de banners em locais de ampla circulação (hall da secretaria e refeitório);

registros das evidências para o memorial da escola.

Em cada uma das ferramentas do composto de comunicação levaremos em conta o público quem se dirigem para a criação da arte e do texto. Afinal, públicos diferentes são atraídos diferentemente e, portanto, exigem meios, textos e diferentes para serem eficientes e eficazes. O Projeto foi elaborado visando oferecer serviços de qualidade em prol da melhoria da aprendizagem de nossos alunos (usuários). Assim sendo, acreditamos que nossa principal ferramenta de comunicação acabará sendo o testemunho de nossos alunos, pais e professores satisfeitos com os resultados dos alunos e da própria instituição. 


\section{Organização e gerência do empreendimento Equipe Gestora}

O sucesso de um projeto é o resultado de um trabalho em equipe; é quando um grupo se transforma em um time. Para o planejamento e execução deste projeto descrevemos o perfil das pessoas responsáveis pelas principais ações e suas respectivas responsabilidades.

\begin{tabular}{|l|l|l|l|}
\hline \multicolumn{1}{|c|}{ Nome } & \multicolumn{1}{|c|}{ Função } & \multicolumn{1}{|c|}{$\begin{array}{c}\text { Formação/ } \\
\text { Experiência }\end{array}$} & \multicolumn{1}{c|}{$\begin{array}{c}\text { Principais atividades } \\
\text { (no Projeto) }\end{array}$} \\
\hline Maristela & Diretora Geral & $\begin{array}{l}\text { Cursando MBA Gestão Empreendedora em } \\
\text { Educação (UFF) e especialista em Gestão de } \\
\text { Ensino Público (UFJF). Desempenha a função } \\
\text { há 3 anos e foi professora regente, } \\
\text { coordenadora pedagógica e diretora adjunta da } \\
\text { escola antes de assumir o cargo. }\end{array}$ & $\begin{array}{l}\text { Gestora responsável pela compra de } \\
\text { equipamentos, contratação de serviços, } \\
\text { prestação de contas das verbas } \\
\text { destinadas à escola e } \\
\text { acompanhamento da execução do } \\
\text { projeto e seus resultados. }\end{array}$ \\
\hline Darcy Ivone & Diretora Adjunta & $\begin{array}{l}\text { Desempenhando a função desde 2004, devido à } \\
\text { grande experiência profissional na esfera pública } \\
\text { (mais de 30 anos de magistério), presta auxílio } \\
\text { tanto nas questões administrativas, quanto nas } \\
\text { pedagógicas. }\end{array}$ & $\begin{array}{l}\text { Responsável por Planejar e } \\
\text { acompanhar o projeto junto aos } \\
\text { professores e disciplinas críticas. }\end{array}$ \\
\hline $\begin{array}{l}\text { Luiz } \\
\text { Gonzaga }\end{array}$ & Diretor Adjunto & $\begin{array}{l}\text { Especialista em gestão de Projetos } \\
\text { Educacionais desempenha a função há 3 anos e } \\
\text { atuava como professor regente da escola antes } \\
\text { de assumir a função. }\end{array}$ & $\begin{array}{l}\text { Responsável por acompanhar a } \\
\text { execução dos reparos, instalação de } \\
\text { equipamentos e acompanhamento da } \\
\text { execução do plano de ações, } \\
\text { cronogramas, resultados e } \\
\text { contramedidas dos possiveis desvios. }\end{array}$ \\
\hline Valéria & $\begin{array}{l}\text { Coordenadora } \\
\text { Pedagógica }\end{array}$ & $\begin{array}{l}\text { Pedagoga exerceu a função de gestora em outra } \\
\text { escola por 5 anos, desempenha a função nesta } \\
\text { unidade desde 2012. }\end{array}$ & $\begin{array}{l}\text { Responsável por acompanhar os } \\
\text { resultados dos alunos e planejar ações } \\
\text { de recuperação de conteúdos. }\end{array}$ \\
\hline Julio & Animador Cultural & $\begin{array}{l}\text { Professor de história, desempenha a função } \\
\text { desde a fundação da escola, além de ser o } \\
\text { responsável pela equipe de Agentes Jovens. }\end{array}$ & $\begin{array}{l}\text { Responsável pela execução do plano } \\
\text { de comunicação da escola e pela } \\
\text { mobilização dos alunos. }\end{array}$ \\
\hline
\end{tabular}

\section{Principais processos}

\section{Segue o perfil da equipe e os principais processos para a execução do projeto}

\begin{tabular}{|l|l|l|}
\hline \multicolumn{1}{|c|}{ Processos } & \multicolumn{1}{|c|}{ Colaborador } & \multicolumn{1}{c|}{ Perfil Necessário } \\
\hline $\begin{array}{l}\text { Realizar atividades com as } \\
\text { turmas e receber os alunos para } \\
\text { pesquisas no contraturno. }\end{array}$ & Fabiana (Agente de biblioteca) & $\begin{array}{l}\text { Conhecimento: responsável pela biblioteca, dinamizadora } \\
\text { dos recursos tecnológicos ali disponíveis, auxiliando } \\
\text { alunos nas pesquisas que complementarão as aulas. } \\
\text { Habilidade: Boa comunicação verbal. Excelente atuação } \\
\text { com alunos. } \\
\text { Atitude: Criatividade, responsabilidade e ética profissional. }\end{array}$ \\
\hline $\begin{array}{l}\text { Utilizar salas de aulas equipadas } \\
\text { e laboratório de informática para } \\
\text { realização de diferentes } \\
\text { atividades e aulas atrativas e } \\
\text { dinâmicas nas diversas áreas do } \\
\text { conhecimento. }\end{array}$ & $\begin{array}{l}\text { Conhecimento: Professores concursados, contratados } \\
\text { temporariamente ou monitores do Programa Mais } \\
\text { Educação, capacitados nas tecnologias e comprometidos } \\
\text { com a melhoria da aprendizagem. } \\
\text { Habilidade: Gostam de inovação e de ensinar de } \\
\text { diferentes formas. } \\
\text { Atitude: Responsabilidade com a aprendizagem de seus } \\
\text { alunos e seu papel de agente de transformação social. }\end{array}$ \\
\hline
\end{tabular}




\section{CIEP 358:espaço de autonomia e transformação}

\begin{tabular}{|c|c|c|}
\hline $\begin{array}{l}\text { Acompanhar a freqüência e } \\
\text { desempenho dos alunos, além de } \\
\text { realizar atendimentos aos pais e } \\
\text { responsáveis quando necessário. }\end{array}$ & $\begin{array}{l}\text { Adriana (Orientadora } \\
\text { Educacional) }\end{array}$ & $\begin{array}{l}\text { Conhecimento: Pedagoga, especialista em Orientação } \\
\text { Educacional, exerce a função desde } 2011 . \\
\text { Habilidade: domina os processos necessários a sua } \\
\text { função. } \\
\text { Atitude: Autonomia, agilidade, organização e } \\
\text { responsabilidade. }\end{array}$ \\
\hline $\begin{array}{l}\text { Acompanhar os agendamentos } \\
\text { das salas e laboratório de } \\
\text { informática, garantindo } \\
\text { possibilidade de acesso a todos } \\
\text { os interessados. }\end{array}$ & $\begin{array}{l}\text { Odisséia (Coordenadora de } \\
\text { turno) }\end{array}$ & $\begin{array}{l}\text { Conhecimento: Pedagoga, especialista em Orientação } \\
\text { Educacional, atuando como Coordenadora de Turno desde } \\
2011 . \\
\text { Habilidade: domina os processos necessários a sua } \\
\text { função. } \\
\text { Atitude: Organização e responsabilidade. }\end{array}$ \\
\hline $\begin{array}{l}\text { Garantir a limpeza dos ambientes } \\
\text { da escola. }\end{array}$ & $\begin{array}{c}\text { Marli e Rosimeire } \\
\text { (ASGerais / terceirizadas) }\end{array}$ & $\begin{array}{l}\text { Conhecimento: colaboradoras terceirizadas responsáveis } \\
\text { pela limpeza dos ambientes da escola. } \\
\text { Habilidade: dominam os processos necessários a sua } \\
\text { função. } \\
\text { Atitude: Agilidade e responsabilidade. }\end{array}$ \\
\hline \multicolumn{3}{|l|}{ Legenda: } \\
\hline \multicolumn{3}{|l|}{ Processo Pedagógico } \\
\hline Processo de Apoio & & \\
\hline
\end{tabular}

\section{PLANO FINANCEIRO}

\section{Investimentos (despesas de capital)}

\begin{tabular}{|c|c|c|c|}
\hline Item & Ano1 & Ano2 & Ano3 \\
\hline Obras e infraestrutura & 330,00 & 0,00 & 0,00 \\
\hline Pintura da sala de informática & 180,00 & & \\
\hline Instalação de 10 tomadas. & 150,00 & & \\
\hline & & & 0,00 \\
\hline Material permanente & $32.711,20$ & & \\
\hline 8 lousas digitais & $20.400,00$ & & \\
\hline 10 Computadores & $12.311,20$ & & \\
\hline & & 0,00 & 0,00 \\
\hline
\end{tabular}

\section{Detalhamento}

- Lousa Digital E - Beam Edge, frete grátis.

- Computador positivo K 32 com Intel Pentium G620, 500 GB, gravador de DVD, leitor de cartões, HDMI, LCD 18.5', e Windows 8.

- Tomada de 3 pontas.

- Pequena reforma da sala de informática: instalação de 10 tomadas e pintura da sala, que será realizada em 3 dias. 


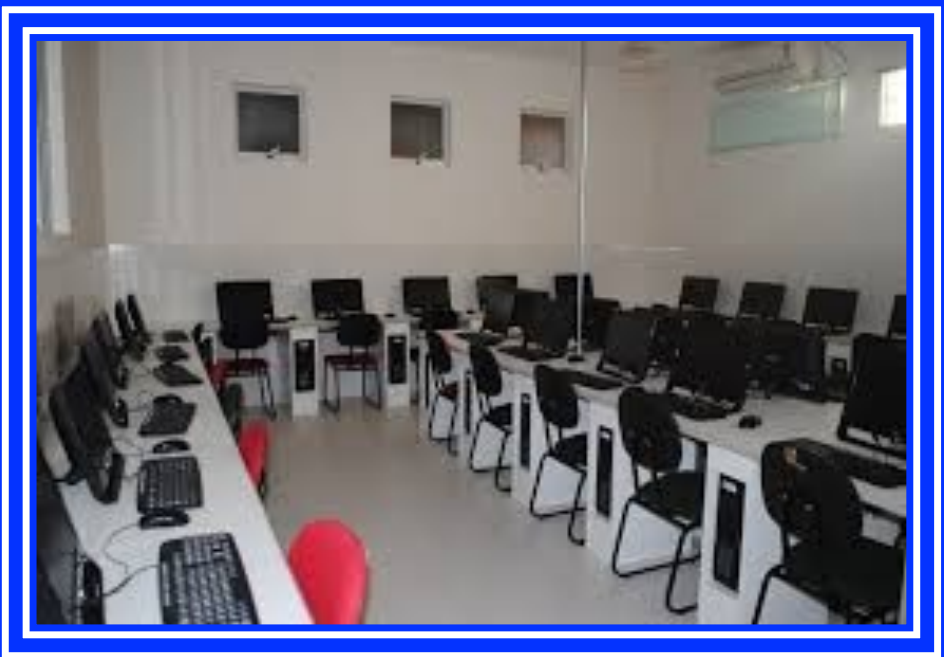

Despesas Correntes

\begin{tabular}{|l|c|c|c|c|}
\hline \multicolumn{1}{|c|}{ Item } & ANO 1 & ANO 2 & ANO 3 & TOTAL \\
\cline { 1 - 4 } I. Total das Despesas Correntes & $14.150,00$ & $14.100,00$ & $14.600,00$ & $42.850,00$ \\
\cline { 1 - 4 } Material de Consumo & $9.800,00$ & $9.600,00$ & $10.100,00$ & $29.500,00$ \\
\cline { 1 - 4 } Passagens e Despesas com Locomoção & $2.850,00$ & $3.000,00$ & $3.000,00$ & $8.850,00$ \\
\cline { 1 - 4 } Serviços de Terceiros & $1.500,00$ & $1.500,00$ & $1.500,00$ & $4.500,00$ \\
\hline
\end{tabular}

\section{Detalhamento}

- Material de papelaria para produção de exercícios e video aulas para o Banco de aulas: 3 compras anuais de resmas de papel $\mathrm{A} 4$, toner para a duplicadora e DVDs.

- Material de papelaria para divulgação do projeto: compra de 4 posters para divulgação.

- Material de papelaria para produção de fanzine: 3 compras anuais de papel A4 e toner para a duplicadora.

- Compra de brindes para premiação dos alunos com melhores desempenhos nas avaliações externas bimestrais: 4 compras anuais de bottons e brindes diversos (mochilas, pen drives, estojos)

- Compra de lanches para visitas pedagógicas (50 alunos e professores acompanhantes): 3 visitas anuais.

- Compra de ingressos para premiação de professores por suas produções de aulas para o banco de aulas: 1 premiação anual. 4

- Transporte de alunos para visitas pedagógicas: 3 visitas anuais.

- Contratação de empresa para capacitação de professores e funcionários nos novos equipamentos: 1 capacitação anual.

\section{Despesas Administrativas e de Pessoal (contrapartida)}

\begin{tabular}{|l|c|c|c|c|}
\hline 1. Total de Despesas Administrativas & $2.160,00$ & $2.311,20$ & $2.472,98$ & $6.944,18$ \\
\cline { 1 - 4 } 2. Total de Despesas com Pessoal & $24.600,00$ & $25.844,40$ & $27.152,32$ & $77.596,72$ \\
\hline
\end{tabular}




\section{CIEP 358:espaço de autonomia e transformação}

\section{Detalhamento}

\section{Despesas administrativas}

- origem dos recursos: SEEDUC - RJ

\begin{tabular}{|l|l|l|l|}
\hline & Ano 1 & Ano 2 & Ano 3 \\
\hline Fornecimento de Energia elétrica & 1200 & 1284 & 1373,88 \\
\hline Fornecimento de água & 600 & 642 & 686,94 \\
\hline Telefone & 360 & 385,2 & 412,16 \\
\hline Total & 2160 & 2311,2 & 2472,98 \\
\hline
\end{tabular}

\section{Despesas de pessoal}

- origem dos recursos: SEEDUC - RJ (servidores públicos e empresa terceirizada)

\begin{tabular}{|l|l|l|l|}
\hline & Ano 1 & Ano 2 & Ano 3 \\
\hline Equipe docente (10 professores) & 15360 & 16128 & 16934,4 \\
\hline Equipe gestora (5 professores) & 7680 & 8064 & 8467,2 \\
\hline Animador cultural (1 profissional) & 1200 & 1260 & 1323 \\
\hline Equipe de limpeza (2) & 360 & 392,4 & 427,7 \\
\hline Total & 24600 & 25844,4 & 27152,3 \\
\hline
\end{tabular}

\section{Recursos necessários}

\begin{tabular}{|l|l|l|l|l|}
\hline \multicolumn{2}{|l|}{ Cálculo da Necessidade de Recursos } & \\
\hline Item & ANO 1 & ANO 2 & ANO 3 & TOTAL \\
\hline I. Total das Despesas Correntes & $14.150,00$ & $14.100,00$ & $14.600,00$ & $42.850,00$ \\
\hline Material de Consumo & $9.800,00$ & $9.600,00$ & $10.100,00$ & $29.500,00$ \\
\hline Passagens e Despesas com Locomoção & $2.850,00$ & $3.000,00$ & $3.000,00$ & $8.850,00$ \\
\hline Serviços de Terceiros & $1.500,00$ & $1.500,00$ & $1.500,00$ & $4.500,00$ \\
\hline II. Total de Despesas Administrativas & $\mathbf{2 . 1 6 0 , 0 0}$ & $\mathbf{2 . 3 1 1 , 2 0}$ & $\mathbf{2 . 4 7 2 , 9 8}$ & $\mathbf{6 . 9 4 4 , 1 8}$ \\
\hline III. Total de Despesas com Pessoal despesas de Capital & $\mathbf{2 4 . 6 0 0 , 0 0}$ & $\mathbf{2 5 . 8 4 4 , 4 0}$ & $\mathbf{2 7 . 1 5 2 , 3 2}$ & $\mathbf{7 7 . 5 9 6 , 7 2}$ \\
\hline $\begin{array}{l}\text { IV. Total de Desp,20 } \\
\text { (investimentos) }\end{array}$ & $\mathbf{0 , 0 0}$ & $\mathbf{0 , 0 0}$ & $\mathbf{3 3 . 0 4 1 , 2 0}$ \\
\hline Necessidade de Recursos (I+II+III+IV) & $\mathbf{7 3 . 9 5 1 , 2 0}$ & $\mathbf{4 2 . 2 5 5 , 6 0}$ & $\mathbf{4 4 . 2 2 5 , 3 0}$ & $\mathbf{1 6 0 . 4 3 2 , 1 0}$ \\
\hline Recursos Edital & $\mathbf{4 7 . 1 9 1 , 2 0}$ & $\mathbf{1 4 . 1 0 0 , 0 0}$ & $\mathbf{1 4 . 6 0 0 , 0 0}$ & $\mathbf{7 5 . 8 9 1 , 2 0}$ \\
\hline \multicolumn{2}{|l|}{} & & & \\
\hline Recursos da Organização (contrapartida) & $\mathbf{2 6 . 7 6 0 , 0 0}$ & $\mathbf{2 8 . 1 5 5 , 6 0}$ & $\mathbf{2 9 . 6 2 5 , 3 0}$ & $\mathbf{8 4 . 5 4 0 , 9 0}$ \\
\hline
\end{tabular}

